\title{
ARTICLE
}

\section{Papshop: Not a 'melon'choly Pap smear workshop!}

\author{
C Gordon, MB ChB, Diploma in HIV Management, Diploma in Mental Health \\ Department of Obstetrics and Gynaecology, Faculty of Health Sciences, Groote Schuur Hospital and University of Cape Town, South Africa
}

Corresponding author: C Gordon (c.gordon@uct.ac.za)

\begin{abstract}
As Head of Undergraduate Education in the Department of Obstetrics and Gynaecology at the University of Cape Town, South Africa, I have a particular interest in the competencies needed to perform primary care gynaecological procedures, one of which is the Pap smear. I was approached by a group of keen volunteer students to assist with Pap smear training to roll out a pilot screening programme at studentrun after-hours clinics in Cape Town and at volunteer rural health promotion clinics. This article describes a novel approach to teaching the Pap smear technique, using fruit and toilet rolls, which can easily be replicated in resource-constrained areas. Students branded the workshops as 'Papshops', and the name has stuck. Increasing numbers of students are now taught by peers already trained in prior Papshops, thereby expanding the teaching workforce. To date, during 2013 - 2014, Papshop students have performed almost 300 Pap smears for eligible women in under-resourced areas.
\end{abstract}

S Afr Med J 2014;104(9):640. DOI:10.7196/SAMJ.8728

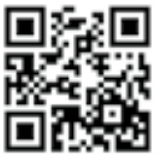

\section{Burden of disease and disease} prevention

It is well known that cervical cancer is the leading cause of cancer mortality in sub-Saharan Africa (SSA), and that the human papillomavirus (HPV) is responsible for the vast majority of cervical pre-cancer and cancer cases. ${ }^{[1]}$ The rollout of the HPV vaccine began in South Africa (SA) in February 2014 for girls $9-10$ years old as part of the school health programme. However, the benefit of reducing the incidence of cervical cancer will take several decades to be apparent. There are more effective ways of screening, such as HPV DNA testing, ${ }^{[2]}$ but there is a lack of infrastructure for such testing in SSA. ${ }^{[3,4]}$ Pap smears will therefore remain a critical secondary cancer prevention intervention for many years to come. It is clear that all relevant healthcare providers (HCPs) must be skilled in performing Pap smears correctly. There is no doubt that adequate training fosters confidence and can dramatically increase screening of eligible women. ${ }^{[5]}$

\section{A volunteer student Pap smear workshop}

As Head of Undergraduate Education in the Department of Obstetrics and Gynaecology at the University of Cape Town, SA, I was approached by a group of volunteer students asking for Pap smear training. These students volunteer for the after-hours student-run Student Health and Wellness Centres Organisation (SHAWCO) clinics. There are six clinics on weekdays: two clinics each on Mondays, Tuesdays and Wednesdays, and a multidisciplinary weekend paediatric clinic. A number of preclinical and clinical students attend, and are supervised by a volunteer clinician. In 2013, a clinic committee decided to initiate a Pap smear clinic as a pilot project at the Masiphumelele clinic in the informal settlement near Noordhoek, Cape Town. Furthermore, groups of students visit rural areas in the Eastern Cape and on the Cape West Coast during their vacations, where they perform health promotion activities, e.g. Pap smears. Our students are taught about the Pap smear procedure on manikins in their 3rd and 5th years of study. Many volunteer students are in their preclinical years and have not yet been exposed to Pap smears, whereas some clinical students felt that they needed a skills revision before performing Pap smears for the pilot project or during their rural visits. They therefore approached me to ask for help in setting up a weekend training workshop.

\section{Issues related to general and gynaecological skills training}

A number of pertinent issues arise around procedural skills training. Manikins are beneficial as they provide a 'safe', non-threatening environment in which to master skills compared with learning on real patients. While manikins are a far cry from the complexities of real patients, they allow for the development of sequential motor memory ${ }^{[6]}$ which can improve confidence when actually performing a procedure. However, manikin training lacks authenticity. ${ }^{[7,8]}$ Another universal problem with skills training is the absence of direct observation of skills performance by teachers due to a lack of time available for supervision.

A particular problem in gynaecology is the embarrassing nature of the gynaecological examination, both for students (especially males) and patients. ${ }^{[9]}$ The latter are often reluctant to be examined in this way by students, who then struggle to practise on real patients, and thus rate their pelvic examination or Pap-taking skills poorly. ${ }^{[10]}$ Healthcare providers are less likely to perform Pap smears if they lack confidence, and consequently valuable screening opportunities may be lost. ${ }^{[9]}$ As teachers, we can try to improve proficiency and confidence in these areas to alleviate what I call 'the fear of fumbling.

\section{Workshop design}

When contemplating how to run the workshop, I incorporated the following features:

- relevant information

- peer-assisted learning

- a step-by-step demonstration of Pap smears

- improved authenticity

- practise of Pap smears to be directly observed and critiqued - fun. 


\section{Relevant information}

Prior to the workshop, I gave a brief talk to contextualise the burden of disease and the reasons behind doing Pap smears, as screening is far more likely to occur if healthcare providers understand the rationale behind the procedure. ${ }^{[5]}$ The talk focused on cervical lesions caused by HPV, burden of disease, primary and secondary prevention, how Pap smears are done, how to complete a cytology request form, and when to refer/when colposcopy is needed.

A flow chart on eligibilty criteria and a worksheet on what equipment is needed, how the procedure is performed, how to counsel a patient and how to complete a cytology form were compiled for students to take with them.

\section{Peer-assisted learning}

The first workshop comprised six students (Fig. 1), all of whom I directly observed. They then supervised each other. Subsequent workshops had up to 20 - mostly preclinical -students, who could be divided up and directly supervised by peers who had previously attended the workshop. Peer-assisted learning (PAL) can be a very effective way of teaching and learning, as it forces student teachers to read up or practise what they will be teaching. Students find peers less threatening than senior staff members, and student teachers have a better idea of the level of their peers. ${ }^{[12]}$ With ever-increasing student numbers, PAL will become increasingly relevant.

\section{Step by step}

The most effective way to teach a skill is to first perform it in its entirety without talking, so that students grasp the flow and duration of the procedure. ${ }^{[6]}$ This mental image becomes the 'film' to which compare their own proficiency. ${ }^{[11]}$ Subsequently, the skill should be explained step by step. Students should then be directly observed performing the skill and corrected as necessary. There were three aspects to the skills demonstration:

- equipment needed

- speculum insertion/removal

- the Pap smear.

\section{Authenticity}

Obviously, no model can give a truly authentic impression of a gynaecological examination. However, to make the experience of the actual Pap smear more authentic, I used blocks of melon wedged into toilet roll inners (Figs 2 and 3). Thus, students could practise

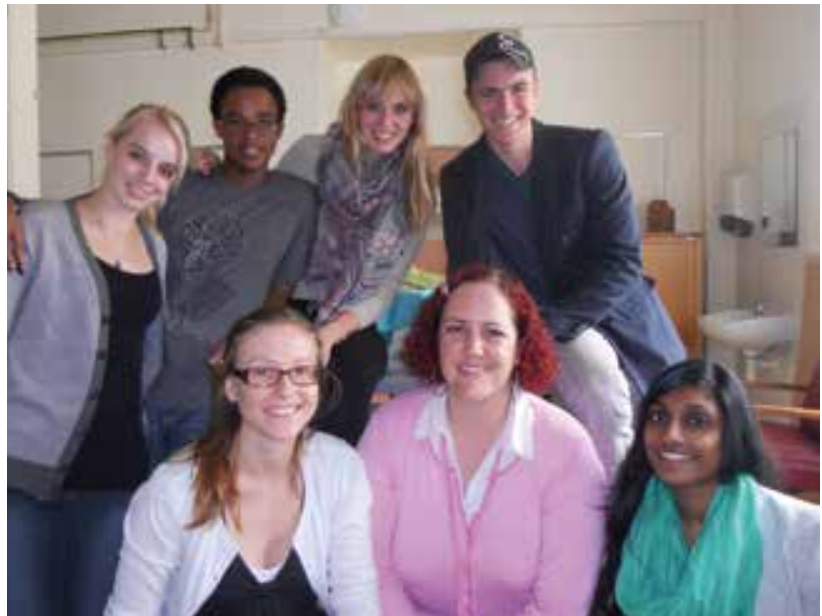

Fig. 1. Back, from left: Bianca Strachan, Russell Githinji, Theresia Rübler, Jason McMaster. Front, from right: Andrea Icely (who coined the term 'Papshop'), Dr Chivaugn Gordon, Prianka Naidu. speculum insertion on the models, but practise the Pap smear on something containing real cells for the experience of transferring actual cellular material onto slides with spatulas and endocervical brushes, and using the fixative on the slides. Of their own accord, the students began simulating patients by holding the vagina/cervices at the usual height and angle of a vagina, inserting the speculum into the toilet roll inner, as opposed to the models, and performing the Pap smears on the melons (Fig. 4).

\section{Evaluation}

Students thoroughly enjoyed the workshop, and found the toilet roll/ melon combination original and great fun! Students felt confident

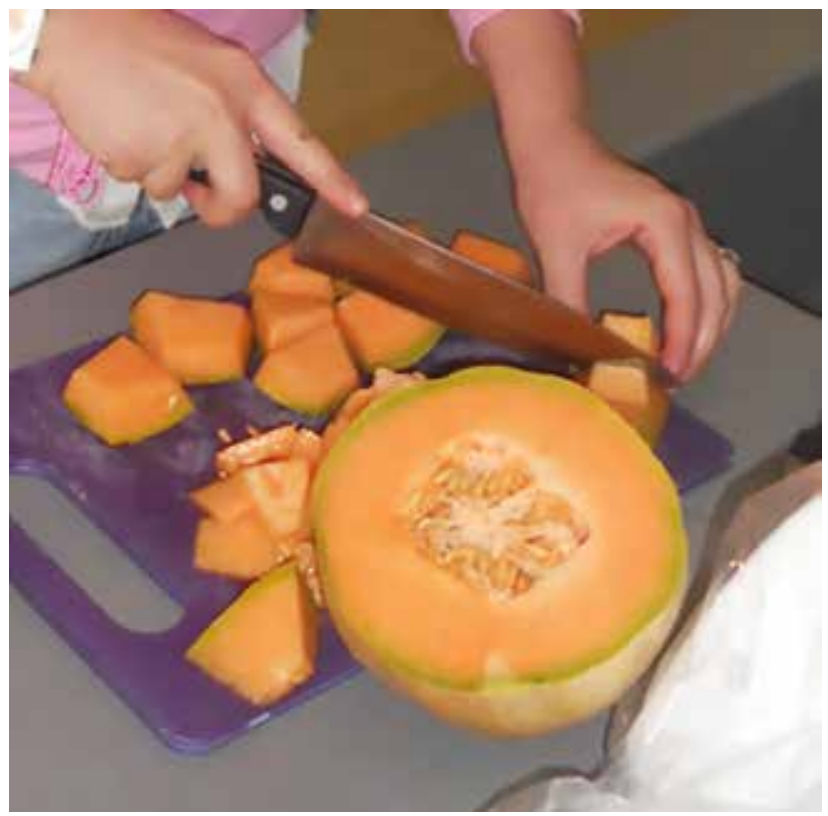

Fig. 2. Making cervices.

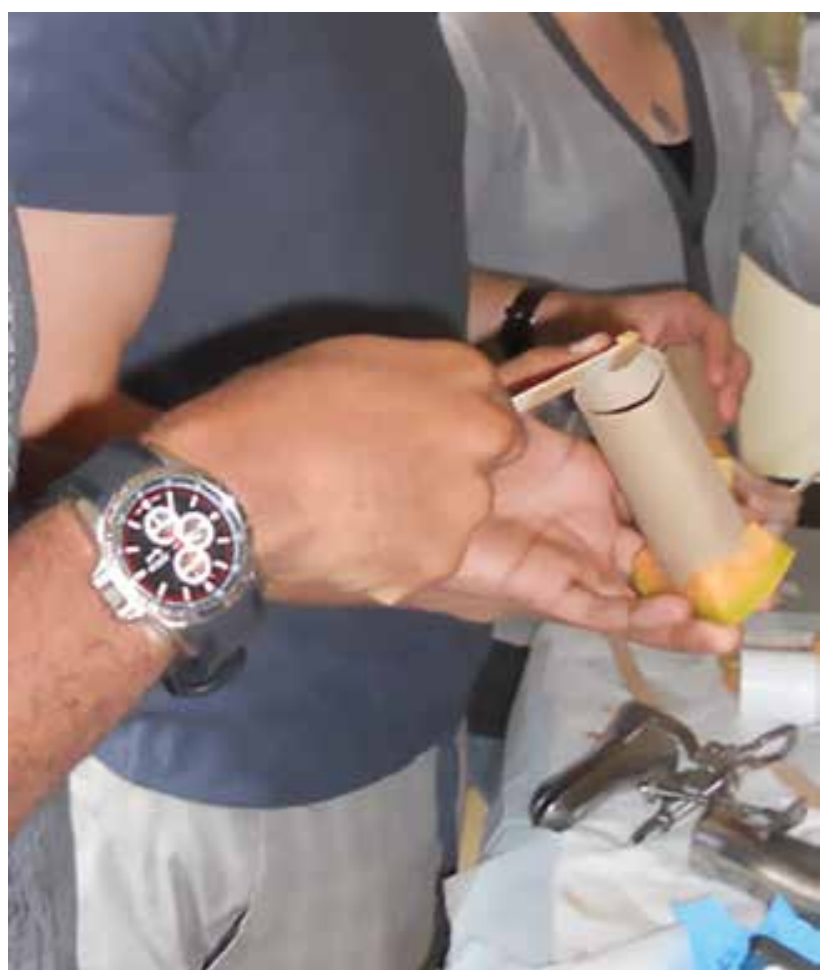

Fig. 3. A 'melon Pap'. 


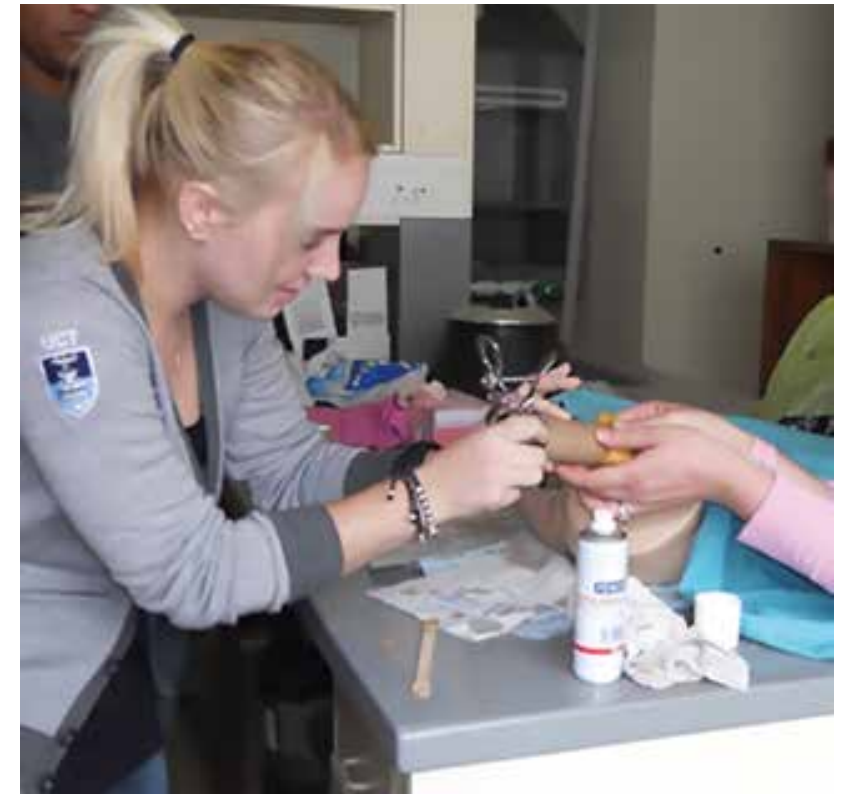

Fig. 4. The beginnings of the angle and height of a real vagina.

in using a speculum and in doing the procedure after the workshop, and experienced the smearing of 'melon Paps' onto slides helpful and authentic. They descibed the melon Pap smears as being more 'real, 'definite' and giving the 'feeling' of the 'texture' of real tissue. Some explicitly said the melons were better than the models for the Pap smear procedure. They enjoyed the informality of being taught by peers in small groups, which allowed everyone to be directly observed. All students said they would recommend the workshop to others. One problem we had in the most recent workshop, however, was an over-ripe melon, where chunks of 'cervix' were disconcertingly dislodged. Some students who were questioned after performing real Pap smears at clinics, found their first exposure to female genitalia and speculum examinations a little overwhelming, as expected, but were comfortable with using a speculum and with the Pap smear procedure itself. They found that the melons had contributed to their proficiency and sped things up. Their first one or two Pap smears were overseen by senior students, but the junior students were soon comfortable with the procedure, thus freeing up the supervisors to see other patients. The student who ran the first workshop branded it 'Papshop', and the name has stuck. To date, five such workshops have been held with me and two colleagues, and students have performed almost 300 Pap smears over two years to date, in rural (Zithulele in the Eastern Cape) or semi-rural (Vredenburg Hospital on the Cape West Coast) areas during their vacations. Clinicians are always on hand to supervise or assist where needed, but the students perform most of the Pap smears.

\section{Open access}

The pre-workshop talk, worksheet and skills procedure have been video-recorded, and are available on request.

\section{Limitations}

Naturally, an audit should be done on the quality of the Pap smears that the students performed at these clinics to assess their actual proficiency in the procedure. This is not currently feasible. Recruitment of patients for Pap smears in Masiphumelele has been slow, but meetings will be held with community health workers to find ways to improve the situation. Many patients have not fulfilled
Pap smear criteria, and care must be taken to operate within the national Pap smear guidelines and not to perform them on every woman requesting a Pap smear, so that the budget is appropriately spent. Despite these challenges, we feel that, even without manikins, Pap smears can be effectively taught by generalists, specialists or nurses, using toilet rolls, melons, and equipment available at any clinic or hospital, as both are a low-cost and fun way to teach Pap smear technique!

\section{Papshop 'shopping list' (assuming resource-constrained area) \\ From home}

$1 \times$ block melon per pair of students (roughly one melon per 20 students)

$1 \times$ toilet roll inner per pair of students

$1 \times$ sharp knife and cutting board

$1 \times$ torch per pair of students (students bring their own)

$1 \times$ cleaning product and cloth

$1 \times$ towel to place under the models (students bring their own)

\section{From the hospital/clinic}

$1 \times$ area to give brief talk, with or without electronic equipment (e.g. equipment for a Power Point presentation)

$1 \times$ teacher per five students

$1 \times$ gynaecological model per five students, if available

$1 \times$ speculum per pair of students, if possible

$1 \times$ fixative, preferably expired, per five students

$1 \times$ slide per pair of students; can be cleaned and re-used in future $1 \times$ spatula and endocervical brush (if brushes available) per pair or group of five students; can be cleaned and re-used in future.

Acknowledgements. I would like to acknowledge all the SHAWCO volunteers for their dedication to patient care, and the time they spend volunteering at clinics. The following students have been instrumental in organising 'Papshops': Andrea Icely, Theresia Rübler, Michelle McNair, and Luke Fletcher. I would also like to thank Drs Helen Wright and Carol Wilson for their assistance in running the workshops, and Natalie Solomon for assisting with this article.

\section{References}

1. De Vuyst H, Alemany L, Lacey C, et al. The burden of human papillomavirus infections and related diseases in sub-Saharan Africa. Vaccine 2013;31(5)S:F32-F46.

2. Bosch FX, Broker TR, Forman D, et al. Comprehensive control of human papillomavirus infection and related diseases. Vaccine 2013;31S:I1-I31. [http://dx.doi.org/10.1016/j.vaccine.2013.10.001]

3. Sankaranarayanan R, Anorlu R, Sangwa-Lugoma G, Denny L. Infrastucture requirements for human papilloma virus vaccination and cervical cancer screening in sub-Saharan Africa. Vaccine 2012;31S:F47-F52. [http://dx.doi.org/10.1016/j.vaccine.2012.06.066]

4. Asonganyi E, Vaghasia M, Rodrigues C, et al. Factors affecting compliance with clinical practice guidelines for guidelines for Pap smear screening among healthcare providers in Africa: Systematic review and
meta-summary of 2045 individuals. PloS One 2013;8(9):e72712. [http://dx.doi.org/10.1371/journal pone.0072712

5. Kawonga M, Fonn $\mathrm{S}$. Achieving effective cervical screening coverage in South Africa through human Kawonga M, Fonn S. Achieving effective cervical screening coverage in South Africa through human
resources and health systems development. Reproductive Health Matters 2008;16(32):32-40. [http:// resources and health systems development. R
dx.doi.org/10.1016/S0968-8080(08)32403-3]

6. George JH, Doto FX. A simple five-step method for teaching clinical skills. Family Medicine 2001;33(8):577-578.

7. Fraser J. Teaching practical procedures in general practice: A primer for supervisors of medical students and registrars. Australian Family Physician 2003;32(8):1-4.

8. Glynn LG, MacFarlane A, Kelly M, Cantillon P, Murphy AW. Helping each other to learn - a process evaluation of peer assisted learning. BMC Med Educ 2006;6:18. [http://dx.doi.org/10.1186/1472 6920-6-18]

9. Lurie N, Margolis K, McGovern PG, Mink P. Physician self-report of comfort and skill in providing preventive care to patients of the opposite sex. Arch Fam Med 1998;7:134-137. [http://dx.doi. org/10.1001/archfami.7.2.134]

10. Abraham S. Vaginal and speculum examination in medical curricula. Aust N Z J Obstet Gynaecol 1995;35(1):56-60. [http://dx.doi.org/10.1111/j.1479-828X.1995.tb01832.x]
(1)

11. Field M, Burke JM, McAllister D, Lloyd DM. Peer-assisted learning: A novel approach to clinical skills learning for medical students. Med Educ 2007;41:411-418. [http://dx.doi.org/10.1111/j.13652929.2007.02713.x] 